\title{
Numerical Investigation on Permanent-Magnet Eddy Current Loss and Harmonic Iron Loss for PM Skewed IPMSM
}

\author{
Jinwoo Lim', Yong Jae Kim², and Sang-Yong Jung ${ }^{3 *}$ \\ ${ }^{1}$ Department of Electrical Engineering, Dong-A University, Busan 604-174, Korea \\ ${ }^{2}$ Department of Electrical Engineering, Chosun University, Gwangju 501-759, Korea \\ ${ }^{3}$ School of Information and Communication Engineering, Sungkyunkwan University, Suwon 440-746, Korea
}

(Received 8 August 2011, Received in final form 16 September 2011, Accepted 14 October 2011)

\begin{abstract}
This paper presents the characteristics of PM eddy current loss and harmonic iron loss for PM step-skewed Interior Permanent Magnet Synchronous Motor (IPMSM) with concentrated windings and multi-layered PM under the running condition of maximum torque per ampere (MTPA) and flux-weakening control. In particular, PM eddy current loss and harmonic iron loss in IPMSM have been numerically computed with threedimensional Finite Element Analysis (3D FEA), whereby IPMSM with concentrated windings and multi-layered PM has been designed to identify the optimized skew angle contributing to the reduced PM eddy current loss and torque ripples, while maintaining the required average torque. Furthermore, numerical investigation on PM eddy current loss and iron loss at MTPA and flux-weakening control has been carried-out in terms of PM step-skew.
\end{abstract}

Keywords : interior permanent magnet synchronous motor, torque ripple, permanent magnet eddy-current loss, iron loss, finite element analysis

\section{Introduction}

IPMSM has the distinctive attractiveness in torque and power density, and particularly wide operating speed range with assistance of the outstanding flux-weakening capability. In practical, IPMSM with concentrated windings has been widely applied for its manufacturing easiness and the size compactness due to short end-windings $[1,2]$. However, it has drawbacks of PM eddy current loss and harmonic iron loss at the running circumstance of high-speed driving with flux-weakening control, and torque ripples on account of non-sinusoidal space harmonics. Actually, PM eddy current loss is the cause of temperature rise at the inner side of PM, sometimes giving rise to the risk of irreversible PM demagnetization. Also, torque ripples should be minimized for better the performance of the harmonic noise and vibration of IPMSM. In addition, IPMSM has the unique rotor construction with the multi-layered and segmented PM for the enhanced reluctance torque production and the flux-

*Corresponding author: Tel: +82-31-299-4952

Fax: +82-31-290-5828, e-mail: syjung@ece.skku.ac.kr weakening capability by improving the rotor saliency, which causes the distorted flux path and the significant harmonic iron loss after all.

Meanwhile, skew has been known as the attractive solution for getting rid of torque pulsation, and PM stepskew of rotor is the feasible configuration for IPMSM in terms of manufacturing usefulness, where the best skew angle comes to be the ultimate design objective to compensate the torque ripples, while maintaining the required torque. Furthermore in this paper, PM step-skew angle of IPMSM with concentrated windings and the multi-layered PM has been designed for reducing PM eddy current loss and torque ripples at the same time.

In addition, numerical investigation on harmonic iron loss for the purposely-redesigned prototype of IPMSM has been done for the representative control strategy of MTPA and flux-weakening control in terms of PM stepskew. Moreover, magnetic flux density waveform at the stator tooth and yoke, and its harmonic components are numerically identified in detail. In particular, 3D FEA has been carried out for the better accuracy in calculating the electromagnetic losses and the torque pulsation. 


\section{Numerical calculation of PM Eddy Current Loss and Iron Loss}

IPMSM has the distinctive features of nonlinear magnetic saturation, more significant around the layered PM in rotor, which gives rise to harmonic magnetic flux waveforms. It should be considered in calculating iron loss coupled with nonlinear FEA for the better accuracy [3-5]. In particular, the locally distorted flux waveform in rotor is decoupled into the $n$-th order harmonic component in the $i$-th element, and then the total iron loss can be obtained by adding up the individual iron loss which can be identified in every element with the numerical formulation as shown in (1). In addition, the PM eddycurrent loss in every element, $W_{P M}$, can be calculated by the obtained $n$-th order component of eddy current densities, $J_{n}$, as shown in (2) [6-9].

$$
\begin{aligned}
W_{i}= & \int_{\text {iron }} \sum_{n} K_{e} D \cdot(n f)^{2} \cdot\left\{B_{r, n}^{2}+B_{\theta, n}^{2}\right\} d v \\
& +\int_{i r o n} \sum_{n} K_{h} D \cdot(n f)^{2} \cdot\left\{B_{r, n}^{2}+B_{\theta, n}^{2}\right\} d v, \\
W_{P M} & =\sum_{n}\left(\int_{\text {mag }} \frac{\left|J_{n}\right|^{2}}{2 \sigma} d v\right)
\end{aligned}
$$

where $f$ is the frequency, and $K_{e}, K_{h}$ denotes the coefficients of eddy-current loss and hysteresis loss, respectively. $D$ is the density of the electrical steel plate, and $\sigma$ is the conductivity of PM material. $B_{r, n}, B_{\theta, n}$ denotes the $n$ th harmonic component of the radial and peripheral magnetic flux density [10].

\section{Numerical Investigation on PM Eddy Current Loss and Iron Loss for PM step-skewed IPMSM}

\subsection{Primitive prototype of IPMSM for evaluation}

The primitive prototype of IPMSM (maximum power: $120 \mathrm{~kW} @ 2500 \mathrm{r} / \mathrm{min}$, maximum speed: $6000 \mathrm{r} / \mathrm{min}$ ), of which specification are summarized in Table 1 , has the widely utilized 16 poles and 24 slots with concentrated windings. It has the two-layered cavities configuration

Table 1. Specification of IPMSM.

\begin{tabular}{cccc}
\hline \hline Phase/Poles & $3 / 16$ & Air-gap length & $1 \mathrm{~mm}$ \\
\hline $\begin{array}{c}\text { Number of stator } \\
\text { slot }\end{array}$ & 24 & Outer Diameter of The Rotor & $264 \mathrm{~mm}$ \\
Maximum output & $120 \mathrm{~kW}$ & Outer Diameter of The Stator & $360 \mathrm{~mm}$ \\
Magnet type & Nd-Fe-B & Stacking Length & $120 \mathrm{~mm}$ \\
\hline
\end{tabular}

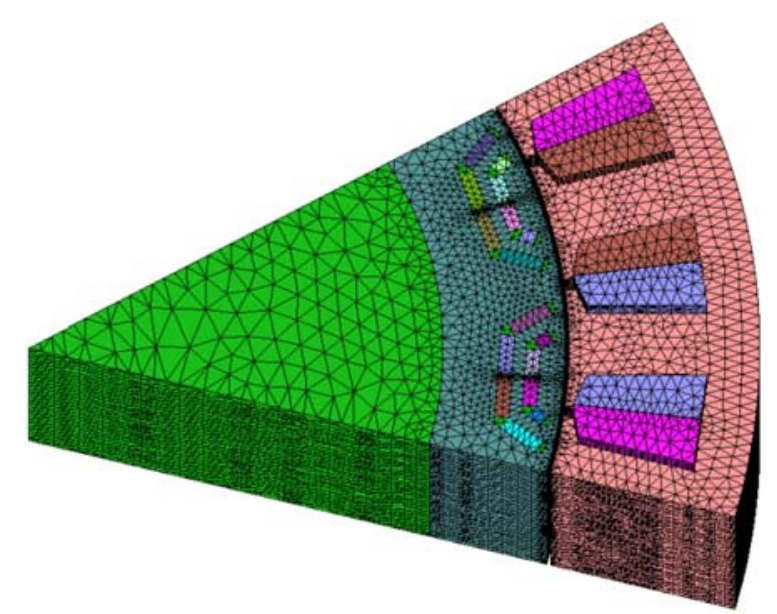

Fig. 1. (Color online) Geometry of primitive prototype of IPMSM.

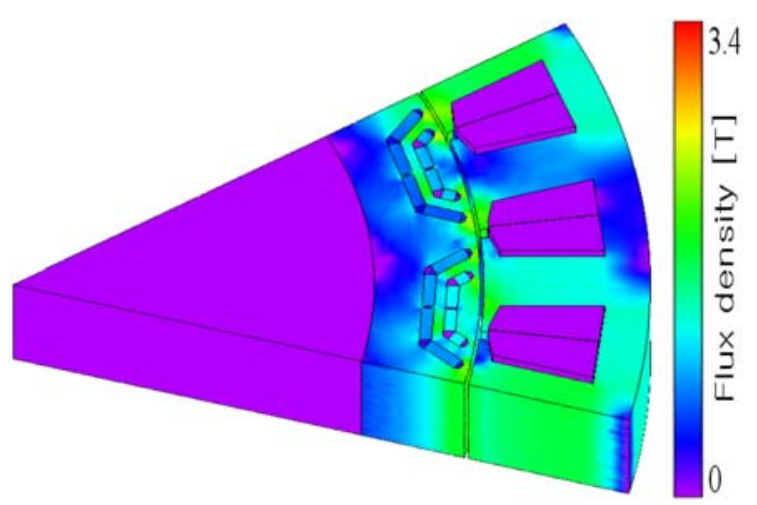

Fig. 2. (Color online) Magnetic flux density of IPMSM under MTPA (Input current: 450Apk, Speed: 2500r/min).

with segmented 8-pieces of PM embedded in rotor as shown at Fig. 1, of which magnetic flux density under MTPA at the base speed (Input current: $450 \mathrm{~A}_{\mathrm{pk}}$, current angle: $29.5 \mathrm{deg}$ ) is shown in Fig. 2. It is shown that the flux concentrates more around the bridge and center-post adjacent to the rotor surface, which gives rise to the harmonic flux giving an influence on harmonic iron loss, PM eddy current loss, and torque ripples as well.

Electromagnetic losses in rotor and torque ripples of the primitive prototype of IPMSM have been computed by 3D FEA with (1) and (2), which are shown in Table 2. In particular, PM eddy current loss is $1.47 \mathrm{~kW}$ amount to the

Table 2. Electromagnetic losses in rotor and torque ripple of IPMSM.

\begin{tabular}{cccc}
\hline \hline $\begin{array}{c}\text { Rotor Iron Loss } \\
(6000 \mathrm{rpm})\end{array}$ & $\begin{array}{c}\text { PM Eddy } \\
\text { Current Loss } \\
(6000 \mathrm{rpm})\end{array}$ & $\begin{array}{c}\text { Average } \\
\text { Toque } \\
(0-2500 \mathrm{rpm})\end{array}$ & $\begin{array}{c}\text { Torque Ripple } \\
(2500 \mathrm{rpm})\end{array}$ \\
\hline $1.85 \mathrm{~kW}$ & $1.47 \mathrm{~kW}$ & $523 \mathrm{Nm}$ & $15 \%$ \\
\hline
\end{tabular}


rotor iron loss at the maximum speed, and torque ripple is up to $15 \%$ of the rated average torque at the base speed, which seems to be hard to control. Significant PM eddy current loss and torque ripple reinforces the primitive prototype of IPMSM to be redesigned purposely, where PM step-skew is regarded as the best solution taking account of manufacturing feasibility.

\subsection{Purposely-redesigned IPMSM with PM step-skew}

Purposely-redesigned IPMSM is shown in Fig. 3 adopting PM 3-step-skew (skew angle: $40 \mathrm{deg}$ in electrical), which results from the numerical investigation compromising to reduce PM eddy current loss and torque ripples at the same time without sacrificing the average torque.

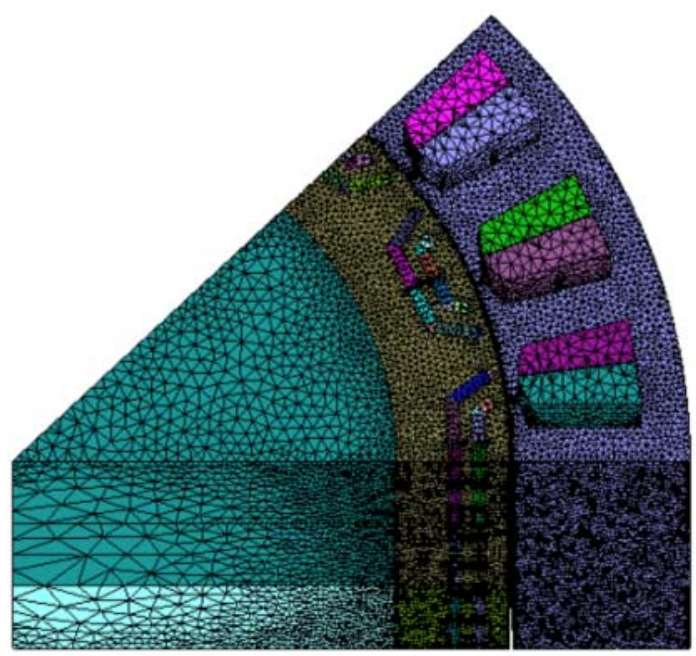

(a)

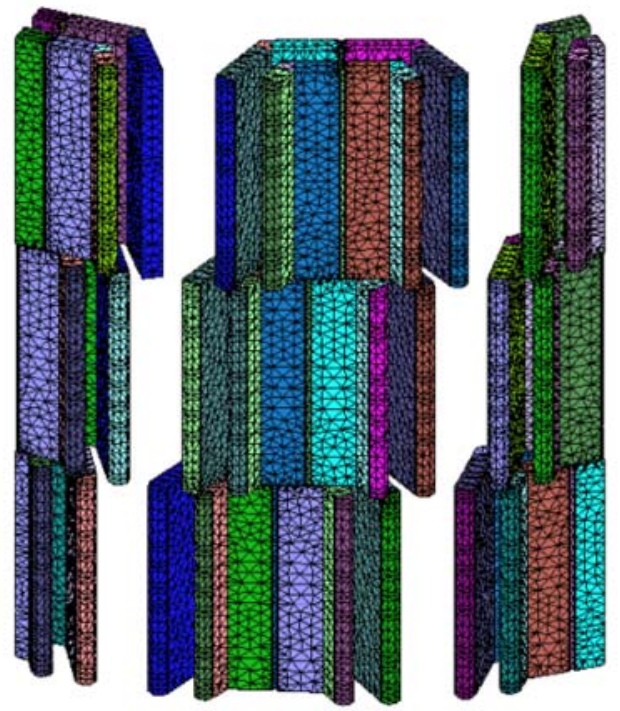

(b)

Fig. 3. (Color online) Purposely-redesigned IPMSM with PM 3-step-skew (40deg in electrical) (a) Geometry of redesigned IPMSM (b) Structure of PM 3-step-skew.

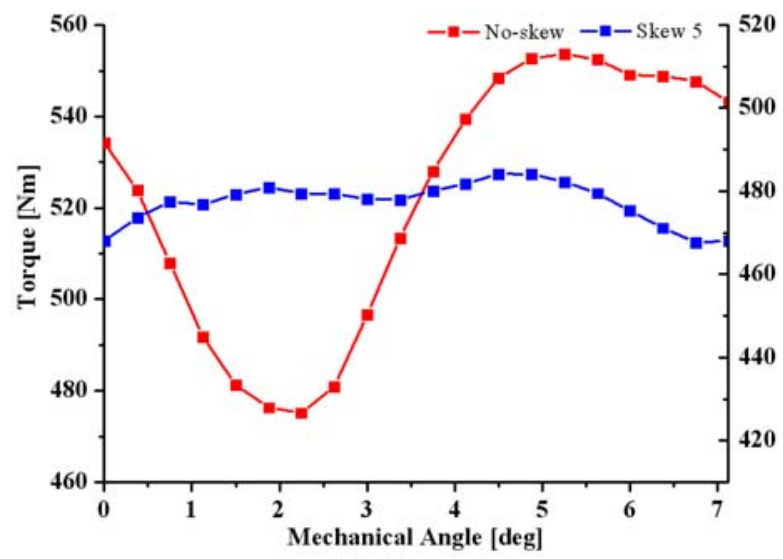

(a)

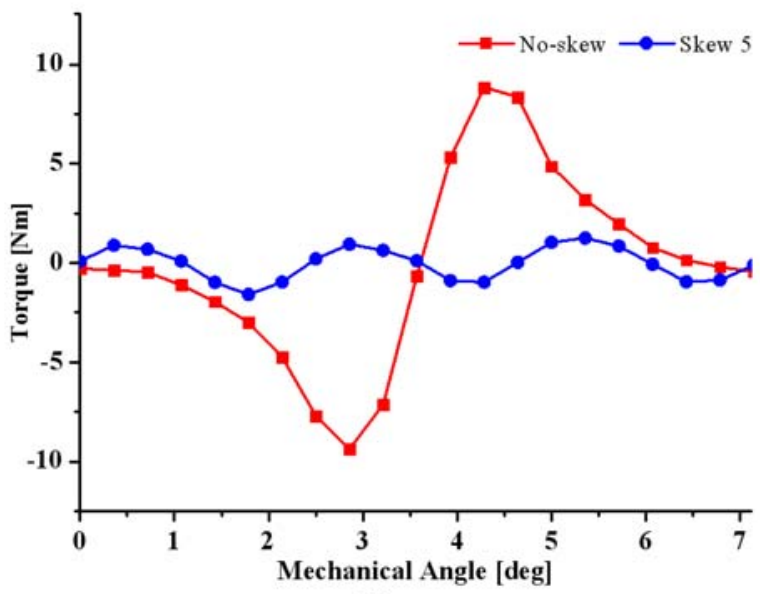

(b)

Fig. 4. (Color online) Comparison results of torque ripples in terms of skewing (a) torque ripples (b) cogging torque.

Actually, 3D FEA has been applied for PM step-skewed IPMSM for better accuracy, paying more attention to the axial directional magnetic flux flow.

Reduction of torque ripples and cogging torque on account of skewing is compared in Fig. 4, manifesting the dramatic elimination of torque pulsation along the rotational angle (in mechanical). Furthermore, reduction of PM eddy current loss in terms of skewing according to the rotational speed is compared in Fig. 5, of which comparison results are summarized in Table 3. PM step-skew has dedicated to reduce torque ripples by $80 \%$, cogging torque by $83 \%$, and PM eddy current loss by $57 \%$, whereas sacrificing the average torque by $8 \%$ only.

3.3. PM eddy current loss and iron loss for PM stepskewed IPMSM at MTPA and Flux-Weakening Control

Comparison results of decoupled stator iron loss, rotor iron loss, and PM eddy current loss in terms of skewing according to rotational speed are shown in Fig. 6. In particular, iron loss in stator and rotor increases, whereas 


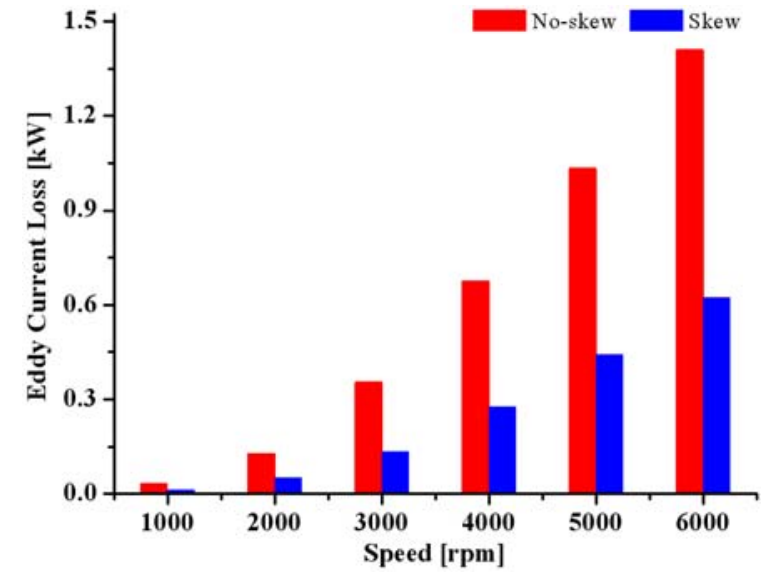

Fig. 5. (Color online) Comparison results of PM eddy current loss in terms of skewing according to rotational speed.

Table 3. Comparison results of torque ripples and PM eddy current loss for redesigned IPMSM.

\begin{tabular}{ccccc}
\hline \hline \multirow{2}{*}{ Division } & \multicolumn{2}{c}{$\begin{array}{c}\text { Torque } \\
(2500 \mathrm{rpm})\end{array}$} & $\begin{array}{c}\text { Cogging Torque } \\
\text { (No-load) }\end{array}$ & $\begin{array}{c}\text { PM Eddy } \\
\text { Current Loss } \\
\end{array}$ \\
\cline { 2 - 4 } & Average & Ripple & Pk-Pk & $(6000 \mathrm{rpm})$ \\
\hline No-skew & $523 \mathrm{Nm}$ & $15 \%$ & $18 \mathrm{Nm}$ & $1.47 \mathrm{~kW}$ \\
Skew & $477 \mathrm{Nm}$ & $3 \%$ & $3 \mathrm{Nm}$ & $0.62 \mathrm{~kW}$ \\
\hline
\end{tabular}

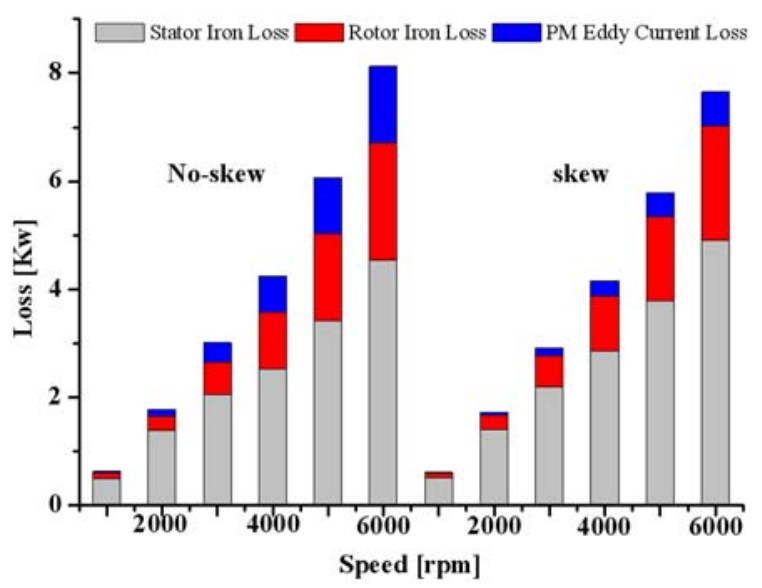

Fig. 6. (Color online) Comparison results of decoupled loss in terms of skewing according to rotational speed (no-skew: 8.25 $\mathrm{kW}$, skew: $7.3 \mathrm{~kW}$ ).

PM eddy current loss decreases noticeably, which contributes to the total loss reduction by $10 \%$ after all by adopting PM 3-step-skew for IPMSM.

For more details for iron loss, fundamental and harmonic ones in stator and rotor are identified in terms of skewing according to rotational speed as shown in Fig. 7. In particular, fundamental harmonic iron loss in stator increases according to rotational speed in MTPA, which is mainly originated by the opening geometry of stator and rotor

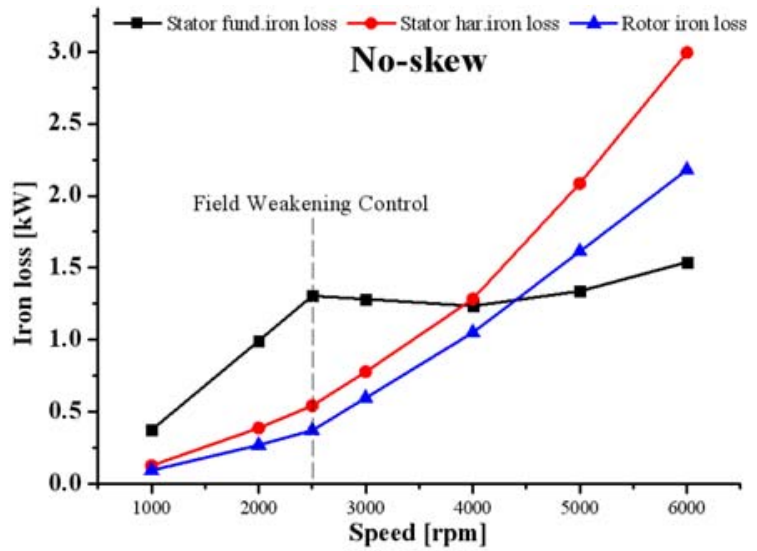

(a)

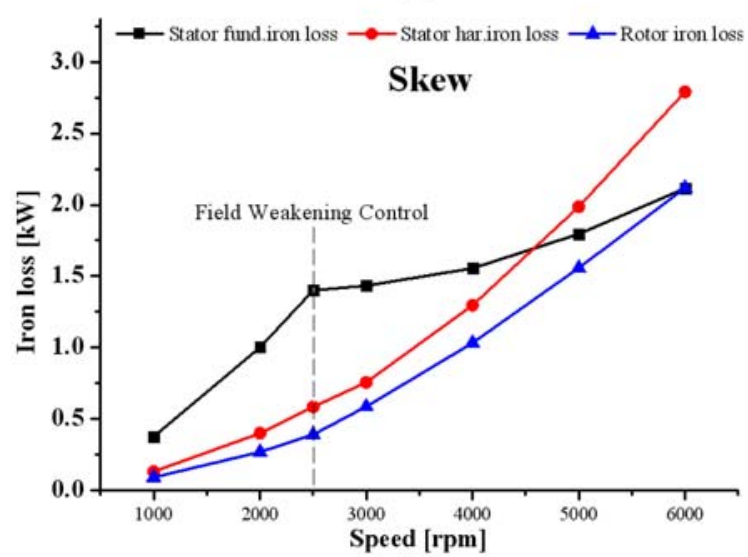

(b)

Fig. 7. (Color online) Comparison results of fundamental and harmonic iron losses according to rotational speed: (a) no skewed IPMSM (b) skewed IPMSM.

along air-gap. However, it decreases at the higher speed exceeding the base speed, since flux-weakening control makes the fundamental field flux decreased by imposing the negative $d$-axis current, whereas harmonic field flux increases in flux-weakening control at the higher speed, and then harmonic iron loss in stator increases analogously. In addition, it is shown that rotor iron loss increases according to rotational speed, which supposes that harmonic field flux flow is dominant in rotor.

Although PM 3-step-skew contributes to outstanding reduction of PM eddy current loss, it gives little effect on iron loss in stator and rotor but the harmonic iron loss in stator increases rapidly according to rotational speed. For more details on harmonic iron loss, numerically obtained iron loss at $2500 \mathrm{r} / \mathrm{min}$ (MTPA) and $6000 \mathrm{r} / \mathrm{min}$ (fluxweakening control) are shown in Fig. 8. It is shown that iron loss distributes conventionally in MTPA, noticeable at rotor surface and tooth-shoe, but most of iron loss in flux-weakening control is occurred at stator mainly due to harmonic iron loss as mentioned before. For better under- 


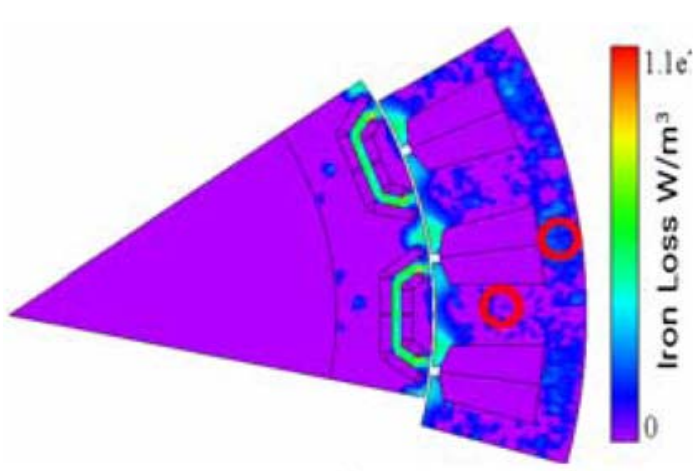

(a)

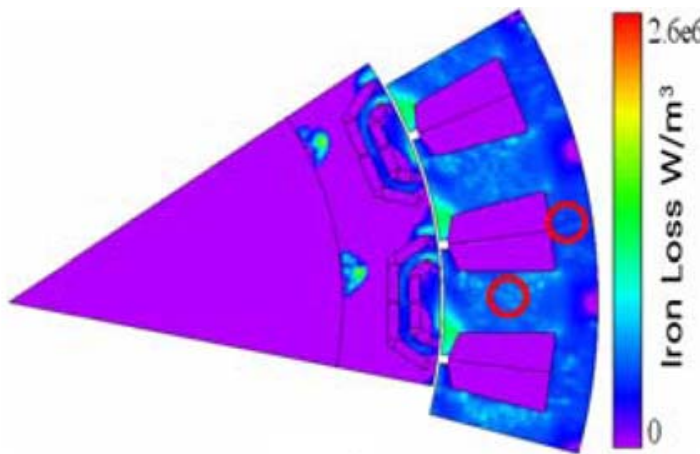

(b)

Fig. 8. (Color online) Iron loss distribution versus rotational speed: (a) Iron loss at 2500r/min (MTPA) (b) Iron loss at 6000r/min (flux-weakening control).

stating of harmonic iron loss in stator, magnetic flux density waveform and its harmonic component are numerically identified using FEA as shown in Fig. 9 and Fig. 10, which is done at teeth and yoke highlighted in Fig. 8 and for MTPA and flux-weakening control, respectively. Analogous to the previous results, harmonic flux density waveform is noticeable for flux-weakening control more than for MTPA, and at tooth more than at yoke because of the harmonic flux concentration across air-gap.
It is shown that the dominant electromagnetic loss component for PM step-skewed IPMSM with concentrated winding is PM eddy current loss and harmonic iron loss in stator, which are also coupled with torque ripples. Accordingly, optimal geometry design of the stator and rotor surface along the air-gap, PM slots, skew angle and number of PM steps will be requisite for the purpose of minimizing PM eddy current loss, harmonic iron loss in stator, and torque ripples as well.

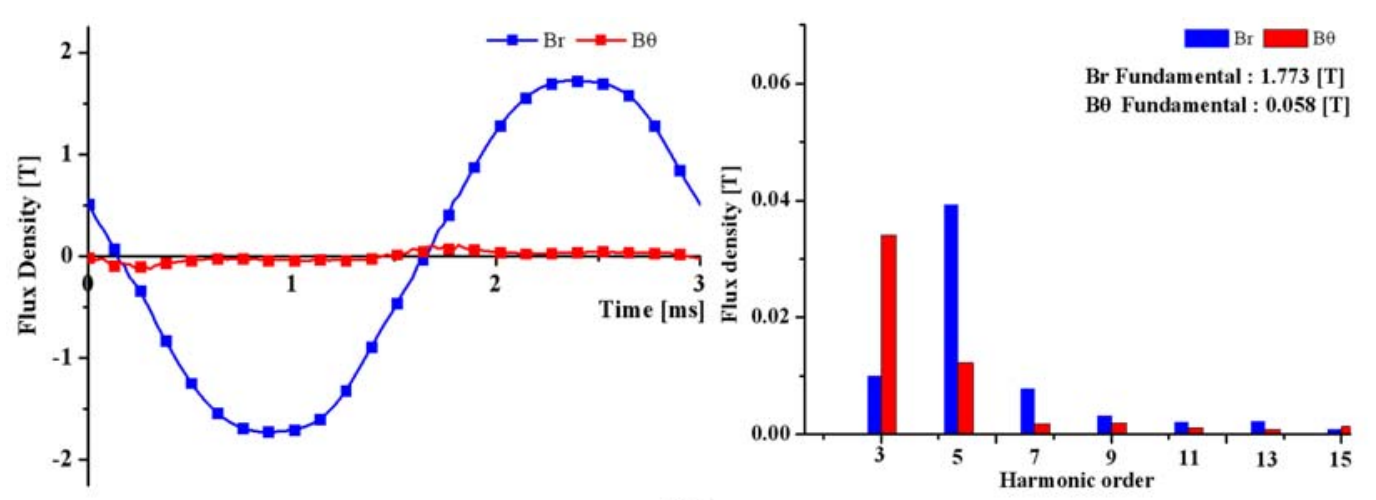

(a)
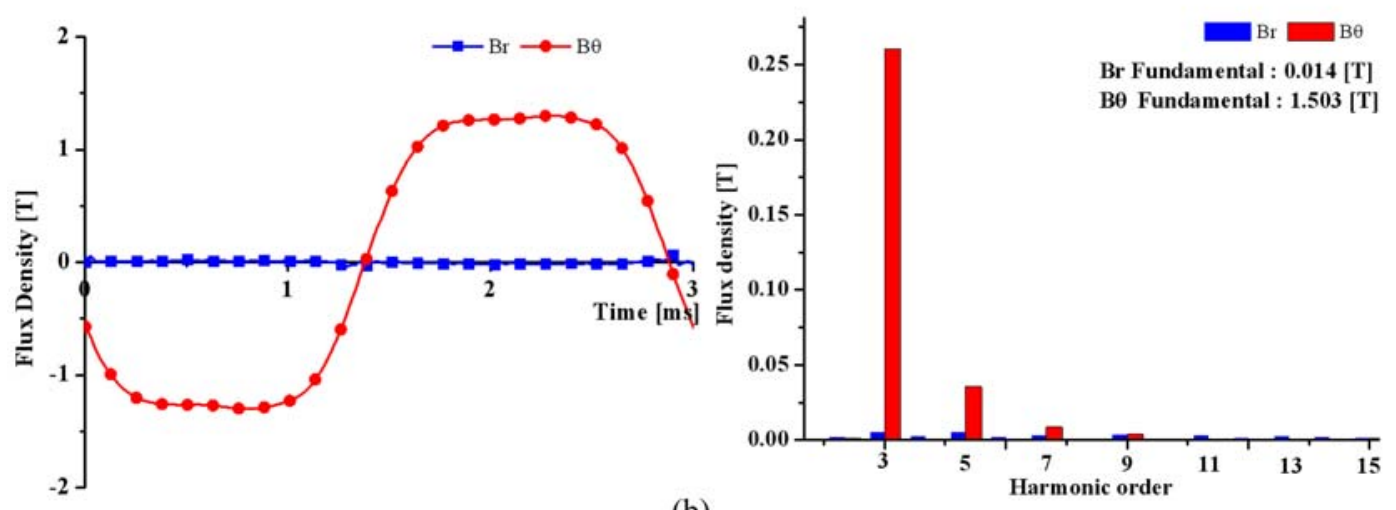

(b)

Fig. 9. (Color online) Flux density waveform and harmonic components at 2500r/min (MTPA) (a) stator tooth (b) stator yoke. 

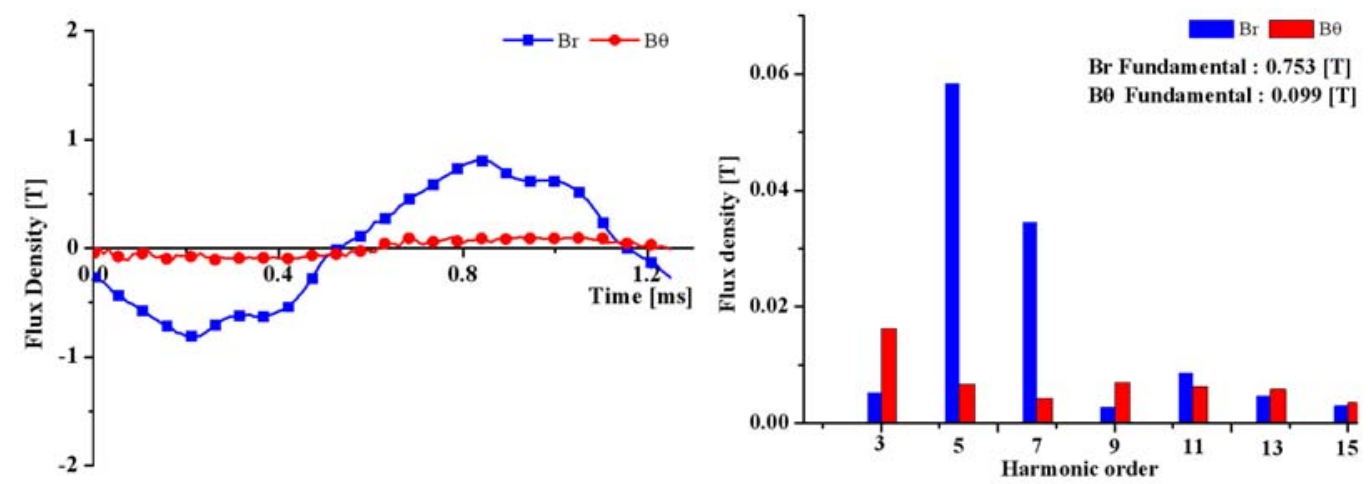

(a)
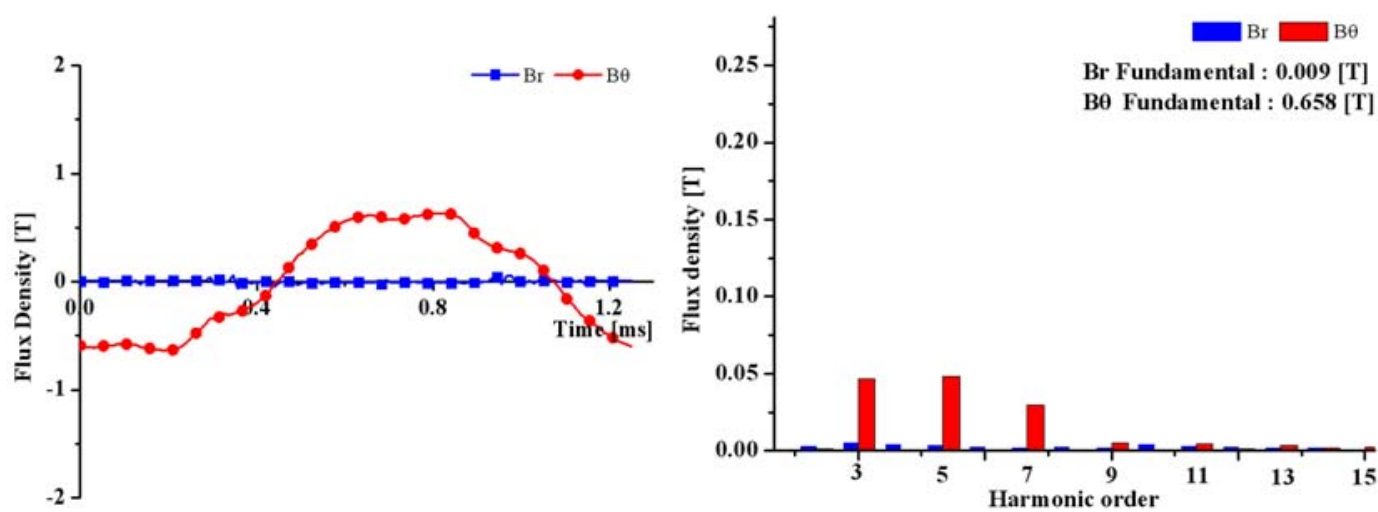

(b)

Fig. 10. (Color online) Flux density waveform and harmonic components at 6000r/min (flux-weakening control) (a) stator tooth (b) stator yoke.

\section{Conclusion}

PM eddy current loss and harmonic iron loss are numerically identified and investigated for PM stepskewed IPMSM with concentrated winding. Based on 3D FEA, PM step-skew angle design of IPMSM has been done for the remarkable reduction of PM eddy current loss and torque ripples at the same time without sacrificing the average torque. Moreover, harmonic iron loss is thoroughly investigated for MTPA and flux-weakening control evaluating the magnetic flux density waveform in stator tooth and yoke. It is shown that the dominant electromagnetic loss components are PM eddy current loss and harmonic iron loss in stator, which are noticeable at flux-weakening control for the higher speed operation and mostly occurred at stator tooth face along the air-gap.

\section{Acknowledgment}

This work was supported by the Human Resources Development of the Korea Institute of Energy Technology Evaluation and Planning (KETEP) grant funded by the Korea government Ministry of Knowledge Economy (No.
20114030200030) and by the Industrial Strategic Technology Development Program, 10035411, Development of Wheel Motor Drive System for Heavy-duty Vehicle equipped with Exchangeable Battery funded by the Ministry of Knowledge Economy (MKE, Korea).

\section{References}

[1] T. M. Jahns, IEEE Trans. Ind. Appl. 23, 681 (1987).

[2] Z. Q. Zhu, Y. S. Chen, and D. Howe, IEEE Trans. Magn. 38, 3285 (2002).

[3] S. Y. Kwak, J. K. Kim, and H. K. Jung, IEEE Trans. Energy Conversion 20, 549 (2005).

[4] B. Stumberger, A. Hamler, and B. Hribernik, IEEE Trans. Magn. 36, 1846 (2000).

[5] F. Fiorillo and A. Novikov, IEEE Trans. Magn. 26, 2904 (1990).

[6] L. Ma, M. Sanada, S. Morimoto, and Y. Takeda, IEEE Trans. Magn. 39, 2036 (2003).

[7] P. Sergeant and A. V. den Bossche, IEEE Trans. Magn. 44, 4409 (2008).

[8] J. Choi, K. Ko, and S. Jang, J. Magnetics 16, 64 (2011).

[9] C. Cho, D. Son, and Y. Cho, J. Magnetics 6, 66 (2001).

[10] J. Jung and T. Kim, J. Magnetics 15, 40 (2010). 